\title{
Detection of Behavior Patterns in Single Women in Mexico
}

\author{
Edgardo Ruiz ${ }^{1}$, Argelia Avila ${ }^{2}$ \\ ${ }^{1}$ Division of Research and Graduate, Iztacala Faculty of Higher Education, \\ National University Autonomous of Mexico, Mexico City, Mexico \\ ${ }^{2} \mathrm{PhD}$ Student in Social Psychology, Universidad Nacional Autónoma de México (UNAM), \\ Ciudad de México, México \\ Email: edgardo@unam.mx
}

Received June $16^{\text {th }}, 2013$; revised July $23^{\text {rd }}, 2013$; accepted August $21^{\text {st }}, 2013$

\begin{abstract}
Copyright (C) 2013 Edgardo Ruiz, Argelia Avila. This is an open access article distributed under the Creative Commons Attribution License, which permits unrestricted use, distribution, and reproduction in any medium, provided the original work is properly cited.
\end{abstract}

\begin{abstract}
The proposal of this work is to detect the existence of patterns of interactive sequential discursive behavior in three single Mexican adult women from retrospective analysis of the interview between them and the interviewer. The applied methodology was observational. It was developed iteratively and thoroughly, a category system as an instrument of observation, and then it was undergone a recategorization process. The number of sessions observed was three, of three hours a duration. Intersessional sequential analysis was used through the SDIS-GSEQ software. Thus we find that the first significant categories in order of occurrence are: Being for her self, Paradox and Independence. The following in significant probability of occurrence position are: Dependency, self-satisfaction, Complementary, Comprehension and Normal. Finally, the categories that are inhibitory occurrence probabilistically negative are: Responsible, Myself, Self-understanding. Finding out these women are learning to live for themselves within a process of emancipation from their families and social structures.
\end{abstract}

Keywords: Identity; Singleness; Women; Gender; Syncretism

\section{Introduction}

In a culture that is characterized by rapid and contradictory changes, women still somehow is qualified to take over the lives of others "being human for others" through a socialization process that guides men and women in the acquisition of skills, behaviors, and values suitable for getting into social life.

Walter, Carter, Papp, and Silverstein (1998) identify as valid some of the features of traditional femininity: put at the service of others, deny autonomy, develop capacity of devotion, delay and give up the desires and personal projects, as well as overestimate a partner and family, which leads to the construction of mother-wife configurations, referred to act as mother of the sisters, brothers, parents, friends, etc. Throughout this process, women are ascribed to the power of the affections, which build servile affiliation (Miller, 1991) not for them, but on discovering and meeting the needs of others.

To Lagarde (2001) the above was established as the main stay of the sense identity for most of the women, a pillar that was built under the ideology of romantic love (Tavora \& Esteban, 2008) and both, its conceptualization, education and loving experience that woman have, promotes the intrinsic part of the social subordination of them. A perpetuation mechanisms carried out by women is acting and playing a set of values and attitudes, as servile affiliation, namely the practices to identify and meet the needs of others in order to feel assured love, even if it means delaying or waiving of desires and personal projects.

Lagarde (1990) provides an underlying explanation of why women's subjectivity is permeated by these beliefs by pointing that the general condition of women is structured around two main axes: the split sexuality of women and the definition of these in relation to power and with the others; their condition is oppressive by vital dependence, subjection, subalternity, also by definition of devoid human beings, capable of waiver, whose basic attitude is to be able to consummate any devotion to others, and unable to become independent of it. The author called learned helplessness to the difficulties of women to establish themselves as subject.

Under these parameters, it is clear that these roles printed in both men and women, limits their personal growth and construct contradictroy and exclusionary subjectivities. These ideologies are transmitted each time through our dialogues and daily practices. And though it is said that the ranges have expanded, that gender roles and their functions are more flexible and it has been producing changes in the notion of masculine and feminine, the change seems to be occurring very slowly.

Among these changes, the conception has played an important role: some women express their sexual needs, and do not often feel guilty or be worried about not establishing an affective commitment, and they have taken a different approach to pleasure sexuality, separating the binomial sexuality-marriage integrating modern and traditional elements that are known as syncretism.

\section{Syncretic Construction}

It is a complex condition, composed not only by patriarchal gender status, but also with modern aspects in our gender condition. The loving and affective relationships that thrive in a world disrupted by the technologies of information and com- 
munication with a utilitarian principle (Bauman, 2005), are permeated by the priority that women and men give to the updating and labor challenges. Scenarios already tested by women facilitate important degrees of individuality. To Lagarde (2005) autonomy offered many times by the income earned from work, implies taking ownership from themselves, to the extent that integrates work as a positive quality of identity, many women are learning to enjoy the material and symbolic goods produced.

In the women work place we consider a number of dimensions; an economic function, which is involved in the construction of social status and prestige. But its relational character is also a field of differentiation of the sexes, as well as exercise and reproduction of power relations, inequality and control (Todaro \& Yañez, 2004).

As for the experience, for Esteinou (2008) the fact that women have a job has become so important that no longer has the same weight as marriage and family do, plus they are evaluating their life partner on the basis of individual, affective and emotional satisfactions than interdependence gives. Lipovetsky (2009) adds, women today opens to love only if this does not jeopardize their personal development, now the girls are more interested in getting their professional development or work, travel, and be able to lead their lives without social pathways predefined.

With all this, the incorporation and increasing development of girls and women into the workplace are happenings involved in new meanings, in the form of conduct, in the development of career paths and negotiations they do with others (family, couple and friends) about their income, leisure, development activities, goals, etc... This may be done as young, unmarried women, but when they want something more permanent, like starting couple life, many choose to marry for companionship and others for economic and social security. In this picture, there are important trends in contemporary women that rebel and oppose to schemes of love for ever.

To Lagarde (2001) women loving subjectivity still populated by myths, beliefs, fantasies, idealizations, through which they experience relationships and amorous affairs. Despite their modern education they are involved in traditional and romantic ideologies, also simultaneously many women experience a collapse of their strengths against love. They live as an act of faith, live frustrating relationships, deficit and inequality loved by a partner, trio, or any other figure erotic-loving.

Lagarde (1996) stresses the discursive and normative intentionality, however legislation has not yet been translated into practice, which seeks to restructure that be for others to be for me, but this transition is marked by a series of contradictions. This be for me means being on par with the others, take care functions to others and oneself, make use of goods, labor, skills for themselves.

Particularly increasing numbers of single women separate love, sexuality and procreation. And it appears in their biography significant long periods without a partner, without dating or without formalizing a commitment but this has not always been this way.

Another contribution of feminism that its return in this analysis of the situation of being single at a certain age, is the questioning that people materialize their sense of life, to live in line with the activities, relationships, needs, expectations, opportunities, duties and prohibitions of each stage of life. Alfarache (2003) elaborated the category cultural life cycle that provides an analytical view of how women make not only bio- logical but cultural cycle that sits on the sexuality "the body and being for others", according to this cultural life cycle is expected that the union with your life partner is about to be specified in women and men youth. So, to be in a position of being single at a certain age is considered by a society state outside the norm.

\section{Single People and Their Tensions}

The genres are under severe pressure from the social context that guides them towards a pair bond, assuming the structure and dynamics of traditional marriage.

By adding the reference "I am single" to "I am", "be for my self", the identity is unbalanced, in part because the woman was formed on the belief that marriage and motherhood meet their most important needs, and they represent the normal way to define and assess their identity and femininity, and on the other hand, because it has the traditional contempt for unmarried, who is presented as an outcast woman and pitiable because the destination has vetoed the possibility to fulfill their feminine functions.

Specifically, that "this is me" on the single woman, is mediated by not being considered a full adult. The single women moves in a indefinite identity that fleet between the daughter of family and be a kind of couple without settling on any option, one consequence of this is the restriction of their freedom to choose and define their life conditions.

However, the gender status of contemporary women consists of the mixture of the patriarchal order and modern aspects of their gender condition (Lagarde, 2005).

Within this modern order, the identity of the self becomes a task which is expressed as the construction of a reflexive project of the self, that is, maintaining a consistent biographical chronicle. In fact, in modern life the notion of lifestyle takes on particular importance as the tradition loses its capacity to be convener and individuals should adopt lifestyles among a variety of options which aspire to protagonize life approach. At the everyday level, women are holding a transformation of intimacy where the main thing seems to be the emergence of the "pure relationship" as a social bond where disappear the external criteria to the point that the relationship exists only for the rewards that itself can provide (Giddens, 1995: p. 11).

The gender perspective has been used to illustrate how linguistic categories determine what we know about the world and, according to Martinez and Bonilla (2000), this perspective offers a critique of the social conditions that hinder communication and liberation of women, looking for equal value as in women as in men. In this regard, as noted Villarreal (2008) study singleness necessarily require analyzing the assumed attitude of men and women with respect to themselves and their living situation, this proposal was retaken in this work to define ways for discursive interaction of single women in relation to his singleness

\section{Objective}

To detect discursive interaction patterns on three single women by being interviewed through the SDIS-GSEQ software.

\section{Hypothesis}

Mexican women are in a process of transition from being for 
themselves and not for others.

\section{Method}

The research was qualitative descriptive. It was established contact through acquaintances that were single. Are single women who decide form other hood but not living as a couple, women and men who were married and then no longer want to be again, people who have lived together and have no children so it's in accurate definition, to this are added other conditions as its geography, religion, language, education, economic status, among others. It was looked at the ethical aspects of research (information, confidentiality and anonymity). The research was attended by three adult women, 34 - 38 years old, professionals, living outside and in the family home. Women were considered to belong to the middle class city in the metropolitan area of Mexico City, since research shows that in this area is expressed more clearly the impact of cultural changes of the last decades. Semi-structured interviews were conducted.

\section{Participants}

The study group was formed by three unmarried Mexican adult. The selection of participants was consistent regarding the admission criteria. As a recording instrument, and in order to ensure maximum accuracy in data collection, there were used two film cameras and two microphones. Both cameras, along with the two microphones were installed in the interview room, where the participants and the interviewer met. In accordance with the ethical standards approved by the American Psychological Association, the participants knew they were about to be filmed and showed where the cameras were, which were positioned discreetly over the furniture and room layout, in order to minimize bias in participants reactivity.

The observation instrument, such as is required by the standards of observational methodology, was developed as a system of categories. The construction of the instrument, in order to fit the requirements of completeness and mutually exclusive (E/ $\mathrm{ME}$ ), initially involved transcribed the entire utterances/voice of participants, which was completed with comments extracted from recordings. Then it began a long process of categorization on verbal dimension that would give rise to a great number of versions of the instrument which was adjusted progressively towards achieving consistency between the name and content of each category and the conditions E/ME (Arias iPujol, 2003). The result is an instrument in which is articulated a system of 8 categories, and ad sub verbal system of 19. All the categories were defined distinguishing the categorical core and the level of openness or plasticity and for each on it was extracted examples and counter examples of recordings made.

Once developed the observation instrument, it was submitted under a recategorization process, carrying out a regrouping of categories (verbal) that combined a field format with eight dimensions, with eight sets of categories, being the following: Loneliness $=$ (worry, PREOC , Self-Determination AUTDE and occupation, OCUP) Work $=($ For others, PAOT, Both AMB and myself MI), Family = Independence, IND Standards, NO, Dependency, DE) Sexuality = (Self satisfaction, AUTS, shared, COM, Hetero satisfaction HET), free time $=($ Self-realization, AUT, Obligation, OBLI, Hetero realization, HETER) Friends = (Hetero comprehension, HETCO, Both AMAM, self-understanding, AUTCO) Singleness $=$ Way to be individual, FORSEI, self-designation, AUTDE, way being for others, FORSEO) Couple $=$ (Paradox, PAR, responsible, RES, Complementary, $\mathrm{COM})$ Loving trajectory $=($ Comprehensive, COMP, Both, AMB, uncomprehending INCOM)

Sequence analysis emerges as one of the most suitable techniques for analyzing data obtained in the study of human interaction. This is a form of microanalysis. It was developed by Sackett $(1979,1987)$ from the influence of the background in the work of Bakeman and Brown (1977).

GSEQ-SDIS software (Bakeman \& Quera, 1992, 1995), as its acronym suggests, brings together two informatic developments. First, the SDIS allows obtaining from a standardized and overall format a sequential data, and secondly, the GSEQ allows powerful description and analysis of sequence data.

The SDIS-GSEQ relies on an analytical technique that was developed by Bakeman (Bakeman, 1978; Bakeman \& Gottman, 1986) and Sackett $(1980,1987)$ from the records that are in the works of Bakeman and Dabbs (1976). In turn there are two perspectives: prospective (looking the meaning "forward", as it occurs occurrence of conduct) and retrospective (in a sense "backward"), which provides a spectacular image of the pattern of behavior that allows to see the two sides of intensive diachronic sequential design.

\section{Results}

Since the aim of this work is to detect the existence of possible discursive sequential behavior patterns among unmarried women interviewed, by analyzing their conversation. The suitable data analysis technique is inter-sesional sequential analysis. This analytical technique proposed by Bakeman (1978) and Sackett $(1978,1979)$ that is widely used in the scientific literature over the last quarter century, aims to detect the existence of stable structures of behavior that have a probability of occurrence greater than it can be expected if the effect of the random act.

Upon selecting lag sequential analysis, selecting excitatory adjusted residuals $(\mathrm{P}>1.96)$ and inhibitory $(\mathrm{P}<-1.96)$ at lags R1 to R5 (see Table 1) we find how criterion behavior FORSEI generates a constant association with FORSEI further alternate with PAR, IND, AUTS in the delays 1, 2 and 3. Following the given behaviour PAR with a consistent association with FORSEI alternating with IND, PAR and AUTS at lags 1, 3 and 4 continuing with the criterion behavior IND that is predictive with FORSEI, COM and MI at lags 1 and 2, continuing this predictive sequential relationship with PAR, AUTS, DE, NOR and FORSEI in delays 3, 4, and 5 respectively, the following behaviour criterion was AUTS that generates FORSEI and MI in delays 1, 4 and 5. The following given behaviour is MI has significant probabilistic sequential relationship with COM, MI and IND, MI, NOR, AUTS and in an inhibitory way with COMP and RES at lags of 1 to 5. The penultimate criterion behavior is AUTS in a predictive relationship with IND, PAR and RES at lags 1, 4 and 5. Last criterion category COMP is in significant sequential relationship with COM, COMP, DE, HETCO and in an inhibitory way with COM at delays 1,2 and 5.

Thus we find that the first categories in order of significant occurrence are; Way to be individual, Paradox and Independence, the following in significant probability occurrence position are Dependency, Self-satisfaction, Complementary Understanding and Normal. Finally, the categories of probabilistically negative inhibitory occurrence are: Responsible, Myself and Self-understanding. 
Table 1.

This table is made from select excitatory adjusted residuals $(\mathrm{P}>0.05)$ and inhibitory $(\mathrm{P}<-0.05)$ at lags R1 to R5.

\begin{tabular}{|c|c|c|c|c|c|}
\hline $\begin{array}{l}\text { Criterian } \\
\text { behavior }\end{array}$ & 1 lag & 2 lag & 3 lag & $4 \operatorname{lag}$ & 5 lag \\
\hline FORSEI & $\begin{array}{l}\text { FORSEI } \\
\text { PAR }\end{array}$ & $\begin{array}{c}\text { FORSEI } \\
\text { IND } \\
\text { PAR } \\
\text { AUTS }\end{array}$ & $\begin{array}{c}\text { FORSEI } \\
\text { PAR } \\
\text { IND }\end{array}$ & FORSEI & FORSEI \\
\hline PAR & $\begin{array}{c}\text { FORSEI } \\
\text { IND } \\
\text { AUTS }\end{array}$ & FORSEI & $\begin{array}{c}\text { FORSEI } \\
\text { PAR } \\
\text { IND }\end{array}$ & $\begin{array}{c}\text { FORSEI } \\
\text { AUTS }\end{array}$ & FORSEI \\
\hline IND & $\begin{array}{l}\text { FORSEI } \\
\text { MI }\end{array}$ & $\mathrm{COM}$ & $\begin{array}{c}\text { PAR } \\
\text { PAR } \\
\text { AUTS }\end{array}$ & $\begin{array}{c}\text { PAR } \\
\text { DE } \\
\text { NOR }\end{array}$ & $\begin{array}{l}\text { FORSEI } \\
\text { NOR }\end{array}$ \\
\hline AUTS & FORSEI & & & MI & FORSEI \\
\hline RES & MI & & RES & IND & MI \\
\hline MI & $\begin{array}{c}\mathrm{COM} \\
\mathrm{MI}\end{array}$ & $\begin{array}{l}\text { RES } \\
\text { RES } \\
\text { COM }\end{array}$ & IND & $\begin{array}{c}\text { MI } \\
\text { NOR }\end{array}$ & $\begin{array}{l}\text { AUTS } \\
\text { COMP }\end{array}$ \\
\hline AUTS & IND & & & $\begin{array}{l}\text { PAR } \\
\text { RES }\end{array}$ & $\begin{array}{l}\text { PAR } \\
\text { RES }\end{array}$ \\
\hline COMP & $\mathrm{COM}$ & $\begin{array}{l}\text { COM } \\
\text { COMP } \\
\text { DE }\end{array}$ & & & $\begin{array}{c}\text { COMP } \\
\text { HETCO } \\
\text { COMP }\end{array}$ \\
\hline
\end{tabular}

(retrospective patterns obtained with 1 to 5 lags); [In black $\rightarrow$ excitatory adjusted residuals]; [In red $\rightarrow$ inhibitory adjusted residuals].

\section{Discussion}

Based on these results we found that single women are in transition from being for herself and being for others, Lagarde (2005) being evident this need while making predictive sequential discursive analysis of them. To Mijares (1990) the single women should undertake a process of resocialization, it means, the acquisition of new knowledge, attitudes and values that will allow them to adapt to the lifestyle they want to adopt, in this process of resocialization a woman must build a new vision of herself and her environment; also her participation in the workplace, her relationship with members of the opposite sex, her sexual behavior and reproductive function; her domestic space and all those spaces and relationships she required to grow, strengthened and made herself as a human being. For this author INDEPENDENT single women are in the process of redefining their identity, as they are on a path that breaks years of cultural conditioning.

Although single woman has not been free of tensions, Mijares (1990), in fact women had to take on their new status amid personal ambivalences and conflicts in the social environment. First, because her behavior is perceived by the environment as destabilizing existing norms and values; and second because her needs for autonomy and self-affirmation are incompatible with the role that society assigns to women; third because it is a style where there is no model to follow and where is needed to inaugurate modalities with its successes and setbacks; fourth and last because in this process of self-realization in which the woman is in contradiction with her own social role, and has to face the problem of being located in the world in a satisfactory way, which means she has to rebuild her identity. Tena (2005) believes that single women in adulthood may present consciously contradictions and conflicts, regardless of the explanations she gives of her single status.

This study has some limitations that are worth noting. For one, the comprehensiveness of content analysis and categorization concrete is merely to complement the analysis with an analysis of discourse. One might consider some other sources of information such as interviews with their parents or friends. Guevara (2010) notes that relationships in your boyfriends status presents glimpses of new discoursesaccordingto social, greaterequity, but that does not mean they give in practice. Be interested to generate knowledge of the experience of women and men singleness single again, either because they cohabit and separated with no children, being single women and men in oldage, or monitor these players in 5 or 10 years and inquire about the permanence or transformation of their meanings and perceptions of its past (its present today) also pose as anarea of future research singleness in women without professional education and other contexts, self-concept in women single that has been little studied.

\section{REFERENCES}

Alfarache, L. A. (2003). Lesbian and feminist cultural identities: An anthropological research. Mexico: Ed Plaza y Valdes.

Arias, E. (2003). Study Interacci óbservacional of a psychotherapy grupd'orientaciópsicoanalítica, from l'conversation analysis. Unpublished doctoral dissertation. Barcelona: Universitat de Barcelona.

Bakeman, R. (1978). Untangling streams of behavior: Sequential analysis of observation data. In G. P. Sackett (Ed.), Observing behavior Vol 2: Data collection and analysis methods (pp. 63-78). Baltimore: University of Park Press.

Bakeman, R., \& Gottman, J. M. (1989). Observing interaction: An introduction to sequential analysis. Madrid: Morata.

Bakeman, R., \& Quera, V. (1996). Analysis interacción. Análisis SDIS and GSEQ sequential. Ma-Madrid: Ra-Ma.

Bakeman, R., Adamson, L. B., \& Strisik, P. (1989). Lags and logs: Statistical approaches to interaction. In M. H. Bornstein, \& J. Bruner (Eds.), Interaction in human development (V. Translation Quera) (pp. 241-260). Laurence Eribaum: Hilisdale.

Bakeman, R., \& Brown, J. V. (1977). Behavioral dia-Logues: An approach to the assessment of mother-infant interaction. Child Development, 48, 195-203. http://dx.doi.org/10.2307/1128898

Bakeman, R., \& Dabbs, J. M. (1976). Observed Social interaction: Some Approaches to the analysis of behavior streams. Personality and Social Psychology Bulletin, 2, 335-345. http://dx.doi.org/10.1177/014616727600200403

Bakeman, R., \& Gottman, J. (1986). Observing interaction: An introduction to Sequential Analysis. Spanish Translation in Ed Morata, 1989. New York: Cambridge University Press.

Bakeman, R., \& Quera, V. (1995). Analyzing interaction: Sequential analysis with SDIS and GSEQ. New York: Cambridge University Press.

Bakeman, R., \& Quera, V. (1992). SDIS: A sequential data interchange standard. Behavior Research Methods, Instruments and Computers, 24, 554-559. http://dx.doi.org/10.3758/BF03203604

Bauman, Z. (2009). Love líquido. México: Economic Culture Fund.

Esteinou, R. (2008). Family types twentieth-century Mexico. In A. Rod, $\&$ D. Robichaux, (Eds.), Families and in the Latin American cultures. Universidad Iberoamericana.

Giddens, A. (1995). The Transformation of intimacy, sexuality, love and eroticism in modern societies. Stanford, CA: Stanford University Press.

Lagarde, M. (1990). Captivity of women: Mother wives, nuns, sluts, dams and crazy. Mexico: General COORDINATION Graduate Studies.

Lagarde, M. (1996). The genus. In M. Lagarde, (Ed.), Gender and feminism. Human development and democracy (pp. 13-38). Madrid: Hours and HOURS. 
Lagarde, M. (2005) To my life partner. Hours and HOURS. Mexico.

Lagarde, \& Rivers, M. (1994). Gender and feminism. Human development and democracy. Hours and HOURS, Madrid, 6.

Lipovetsky, G. (2009). The post-romantic love. Love and power at the turn of the millennium (pp. 3-8). Lima: Publishing Fund.

Martinez, B., \& Bonilla, A. (2000). Sex/gender system, identities and construction of subjectivity. Valencia: On Education. Materials.

Mijares, E. (1990). The single independendiente. Sociological Thesis. Mexico City: UNAM

Sackett, G. P. (1978). Observing behavior (Vol. 2): Data collection and analysis methods. Baltimore: University of Park Press.

Sackett, G. P. (1979). The lag sequential analysis of contingency and cyclicitytion on behavioral interaction research. In J. D. Osofsky (Ed.), Handbook of infant development (pp. 623-649). New York: Wi-law.

Sackett, G. P. (1980). Analysis of sequential social in-teractiondata: Some issues, Recent Developments, and causal inference model. In J.
Osofsky (Eds.), Handbook of infant development (pp. 855-878). New York: Wi-law.

Tavora, \& Esteban (2008). Romantic love and social subordination of women: Reviews and proposals. Area 3. Journal of Group and Institutional Issues, from 14.1 to 19 .

Tena, G. O. (2002). Moral norms related to women's reproductive practices and single men: Religion as wage labor and dimensional analysis. Thesis for the degree of Doctor of Sociology. UNAM.

Todoro, R., \& Yunes, S. (2004). The work is transformed. Production relations and gender relations. Santiago: Ediciones CEM.

Villareal, C. (2008). Being single in midlife women. Reflections Reviews, 87, 99-111.

Walters, M., Carter, B., Papp, P., \& Silverstein, O. (1996). The invisible web. Gender-related patterns in family relationships. Polity Press. Family therapy. 